This is a self-archived - parallel published version of this article in the publication archive of the University of Vaasa. It might differ from the original.

\title{
Influence of lunar semidiurnal tides on groundwater dynamics in estuarine aquifers
}

Author(s): Zhang, Xiaoying; Dong, Fan; Dai, Heng; Hu, Bill X.; Qin, Guangxiong; Li, Dan; Lv, Xiaoshu; Dai, Zhenxue; Soltanian, Mohamad Reza

Title: Influence of lunar semidiurnal tides on groundwater dynamics in estuarine aquifers

Year: $\quad 2020$

Version: Accepted Version

Copyright (C) 2020 Springer. This is a post-peer-review, pre-copyedit version of an article published in Hydrogeology Journal. The final authenticated version is available online at: http://dx.doi.org/10.1007/s10040-020-02136-8

Please cite the original version:

Zhang, X., Dong, F., Dai, H., Hu, B. X., Qin, G., Li, D., Lv, X., Dai, Z. \& Soltanian, M. R. (2020). Influence of lunar semidiurnal tides on groundwater dynamics in estuarine aquifers. Hydrogeology Journal 28(4), 1419-1429. https://doi.org/10.1007/s10040-020-02136-8 


\title{
Influence of lunar semidiurnal tides on groundwater dynamics in estuarine aquifers
}

\author{
Xiaoying Zhang' \& Fan Dong' \& Heng Dai ${ }^{2}$ \& Bill X. Hu² \& Guangxiong $\mathrm{Qin}^{2}$ \& Dan Lí \& Xiaoshu Lü ${ }^{1,4}$ \& Zhenxue Dai' \& \\ Mohamad Reza Soltanian ${ }^{5}$
}

\begin{abstract}
The influence of lunar semidiurnal tides on coastal groundwater aquifers has been conceptualized for decades. However, a thorough understanding of the impact of tides on groundwater dynamics due to the widely distributed waterways and heterogeneous sediments in estuarine aquifers, is still needed. This study shows the tidal impact on groundwater dynamics in the Pearl River estuary in southeast China through wavelet and time series analysis. The groundwater level and electrical conductivity (EC), as well as tidal levels, were monitored in several observation wells and tidal stations to determine how the estuarine groundwater levels respond to tidal forcing. The results show that the groundwater fluctuations have short periodicities of 0.51 and 1 day corresponding to major tidal constituents of $\mathrm{M}_{2}$ (semidiurnal) and $\mathrm{K}_{1}$ and $\mathrm{O}_{1}$ (diurnal) signals, respectively. The significant impacts decrease with increasing distance inland of the locations of the wells. Additionally, the coherence analysis displays a higher correlation between tides and groundwater levels for the spring tide than for the neap tide. The tidal infl uences on groundwater EC are weak compared to those on groundwater levels. In addition, when the tidal level increases, the EC decreases in wells located in the estuarine entrance. This is related to the high salinity of retained paleo-seawater in the strata lenses. A conceptual model is proposed to illustrate the complex groundwater flow dynamics. The model may provide useful insights into the understanding of similar systems located in geographically different coastal regions.
\end{abstract}

Keywords Lunar semidiurnal tides $\cdot$ Groundwater monitoring $\cdot$ Tidal monitoring $\cdot$ Coastal aquifers $\cdot$ China

\section{Introduction}

Low-lying deltas are usually the most developed areas in the world, where groundwater is an important resource for

$*$ Heng Dai

hengdai@jnu.edu.cn

$\approx$ Bill X. Hu

bill.x.hu@gmail.com

1 College of Construction Engineering, Jilin University, Changchun 130026, China

2 Institute of Groundwater and Earth Sciences, Jinan University, Guangzhou 510632, China

3 Guangzhou Institute of Water Sciences, Guangzhou 510220, China

4 Department of Electrical Engineering and Energy Technology, University of Vaasa, P.O. Box 700, FIN-65101 Vaasa, Finland

5 Departments of Geology and Chemical and Environmental Engineering, University of Cincinnati, Cincinnati, OH 45221, USA domestic, agricultural and industrial usages (Essink et al. 2010). In particular, the interaction between seawater and groundwater is important for controlling saltwater intrusion and mitigating contaminants in low-relief estuarine aquifers (Ataie-Ashtiani et al. 1999; Werner et al. 2013; Parizi et al. 2019). The groundwater dynamics near the coast are greatly influenced by tides. This has been observed and accounted for in aquifer management for decades (Kim et al. 2005; Briciu 2014). Because of the elastic storage coefficients of geological strata and the compressibility of solids under tidal forces, the combined effects of tide oscillations and landward groundwater forces cause periodic fluctuations in the groundwater dynamics in estuarine aquifers (Van der Kamp and Gale 1983; Kim et al. 2000; Jay et al. 2015).

Prior studies have simulated the impact of tidal fluctuations on coastal groundwater levels using periodic movements of tides as the main system stress (Li et al. 2000, 2012). When the pressure signals created by the periodic fluctuations of tides propagate inland, their amplitudes are attenuated and phase shifts occur between the tide and groundwater levels (Carr 
and Van der Kamp 1969; Kim et al. 2005; Wallace et al. 2019). A typical damping distance for the tidal fluctuations at the water table in an unconfined aquifer system is only a few hundred meters, while in a confined aquifer system, this distance can extend landward for several kilometers (Nielsen 1990; Dai and Samper 2006). Moreover, the tidal effects can be much greater if a gentle-sloping beach exists (Liu et al. 2012; Mao et al. 2006). Tide-induced fluctuations also influence the salinity of groundwater because the transition zone between saltwater and freshwater has been observed to move back and forth with tidal variation (Ataie-Ashtiani et al. 2001; Robinson et al. 2006; Kang and Lin 2007). Additionally, as the inshore distance increases, the tidal effect gradually decreases, and the groundwater level is more influenced by barometric variations (Dong et al. 2015). Holman et al. (2011) extended the relationship with groundwater level to climatic indices such as the North Atlantic Oscillation and East Atlantic pattern.

The impacts of tides on groundwater aquifers are mainly studied in wells along coastlines (Gribovszki et al. 2010); however, the response of tidal influences on the aquifer of an estuary is more complex. Waterways are widely distributed as a tidal river network in the estuary; additionally, the estuarine subsurface geologic conditions are often complex as they include interbedded marine and terrestrial deposits and thus form isolated aquifer lenses (Dai et al. 2014). Therefore, groundwater dynamics are affected not only by hydrologic stress of tides in the ocean and waterways but also by the complex hydrogeologic conditions. Moreover, many estuaries are influenced by intensifying human activities which alter hydrodynamic and morphodynamic processes (Byun et al. 2004; Brown 2006); therefore, effects of the semidiurnal lunar tidal cycle on groundwater dynamics on estuaries are complex and more studies are needed especially with regard to the groundwater level and salinity variations with short-term periodicities. Understanding the detailed and short periodic relationship between coastal groundwater dynamics and tidal forcing can provide useful knowledge for resolving coastal environmental and associated ecological problems-for example, oil spill remediation in estuaries, heavy metal enrichment of sediments, seawater-groundwater circulation, saltwater intrusion, groundwater discharge which are affected by tidal forcing (Turner 1995; Jiao and Tang 1999; Li et al. 2001; Burnett et al. 2003; Li et al. 2007; Antonellini et al. 2015; Zhang et al. 2017).

In this research, the Pearl River Delta, one of the most developed regions in China, was chosen as the study area. The booming economy and increasing human settlement overwhelmingly affected Pearl River Delta to the point that it is now one of the most complex river networks in the world. The goal of this study is to understand the temporal dynamics tides and the resulting groundwater levels in the Pearl River estuary. A wavelet-based time series analysis was implemented to explore the correlations between tides and groundwater dynamics. Although this research focuses on a certain coastal area, the implemented methodologies could be applied in other studies.

\section{Methods}

\section{Study site investigations}

The study region is located between two main waterways, Jiaomen and Humen, in the Pearl River estuary, which lies in the southern coastal area of China (Fig. 1). The study region is a typical subtropical area with annual precipitation ranging from 1,542 to $2,088 \mathrm{~mm}$ (GWP 2016). The precipitation in this area demonstrates a strong seasonal variation. Approximately $75-95 \%$ of the rainfall occurs from April to September (the wet season), while only $5-25 \%$ of rainfall is delivered during the dry season from October to March (GWP 2016). The tide in this area is dominated by the lunar semidiurnal tidal constituent. The average annual tidal range is 1.2$1.6 \mathrm{~m}$, with a maximum tidal range of $3.4 \mathrm{~m}$ (GWP 2016).

Geologically, the study area developed under the interactions between the rivers and the South China Sea during the Late Quaternary. The thickness of Quaternary sediments varies from several meters to $76.1 \mathrm{~m}$ (Liu et al. 2013). A simplified cross-sectional profile of the stratigraphic units of sediments in the study area is provided in Fig. 2. Small amounts of bedrock of Sinian to Cretaceous ages crop out around and within the delta. The sediments in this area generally consist of layered marine and alluvial sequences, which include layers of sand and gravel alluvial sediments, silt, and clay marine sediments, overlying weathered gneiss, mudstone, and conglomerate.

Five hydrogeological wells were drilled in the Pearl River estuary, and their locations are shown in Fig. 1. Following the order of S50, Q149, Q143, Q138, and B1 from the south to the north, the geologic conditions were constructed from well logs (Fig. 2). The elevations and distances relative to the sea for these wells increased from seaside to inland with a gradient of $2 \times 10^{-4}$. The scope of this investigation included the collection of continuous groundwater levels and electrical conductivity (EC) in four existing wells, S50, Q149, Q138, and B1, from May 25 to July 25, 2017, at an hourly interval, including a complete spring (maximum tidal change) to neap (minimum tidal change) cycle. Additionally, pumping tests were conducted to evaluate the hydraulic conductivity and storativity in the four monitoring wells. A portable rain gauge was set up at a location in Wangqingsha (WQS) near the Hongwili waterway to measure the daily precipitation. Tidal and river fluctuations were collected from three gauging stations at Shuiniutou (SNT), Huangpu (HP) and Guangzhou (GZ) in the same time period. 


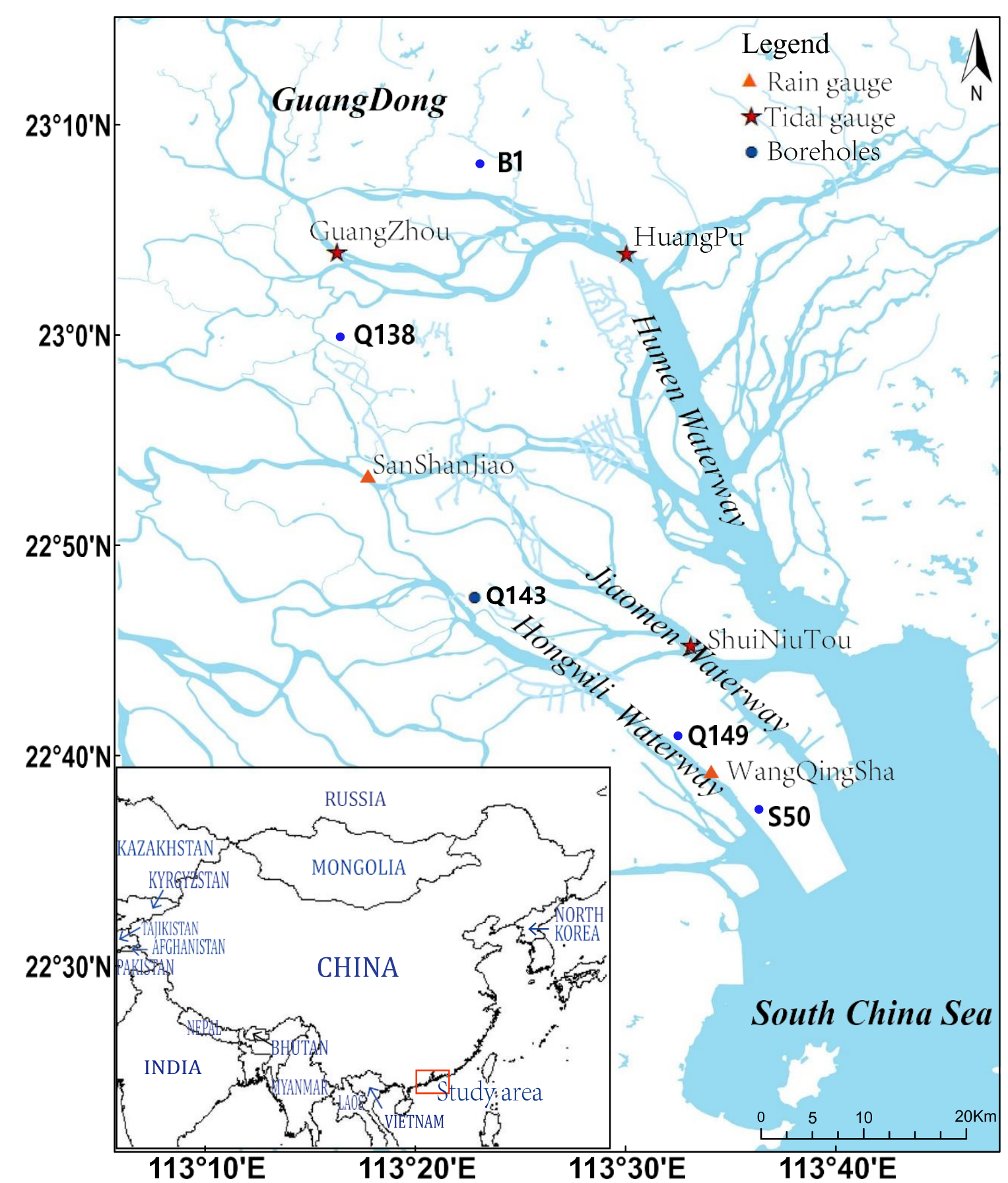

Fig. I Location map of the study region along with representation of hydrological and groundwater monitoring stations

\section{Cross wavelet transform and wavelet coherence}

The wavelet analysis method decomposes a time-series signal into different resolutions by controlling scaling and shifting (Daubechies 1992). The method has the flexibility to choose the mother wavelet, which is the transform function (Galli et al. 1996). The wavelet transform is used to detect the patterns across temporal scales, which are critical to identifying

the components of hydrological records, and it provides localized time and frequency information without requiring the time series to be stationary (Torrence and Compo 1998; Nejad and Nourani 2012). The cross-wavelet transform (CWT) estimates the cross-wavelet power of two time series. For two given time series, $x_{n}$ and $y_{n}(n=1, \ldots, N)$, the cross wavelet transform $W^{X Y}$ is calculated as:

$W_{n}^{X Y}(s)=W_{n}^{X}(s) W_{n}^{Y^{*}}(s)$

where $W_{n}^{X}(s)$ is the CWT of time series $x_{n}$ and $W_{n}^{Y^{*}}(s)$ is the complex conjugate of time series $y_{n}$. By varying the wavelet scale 


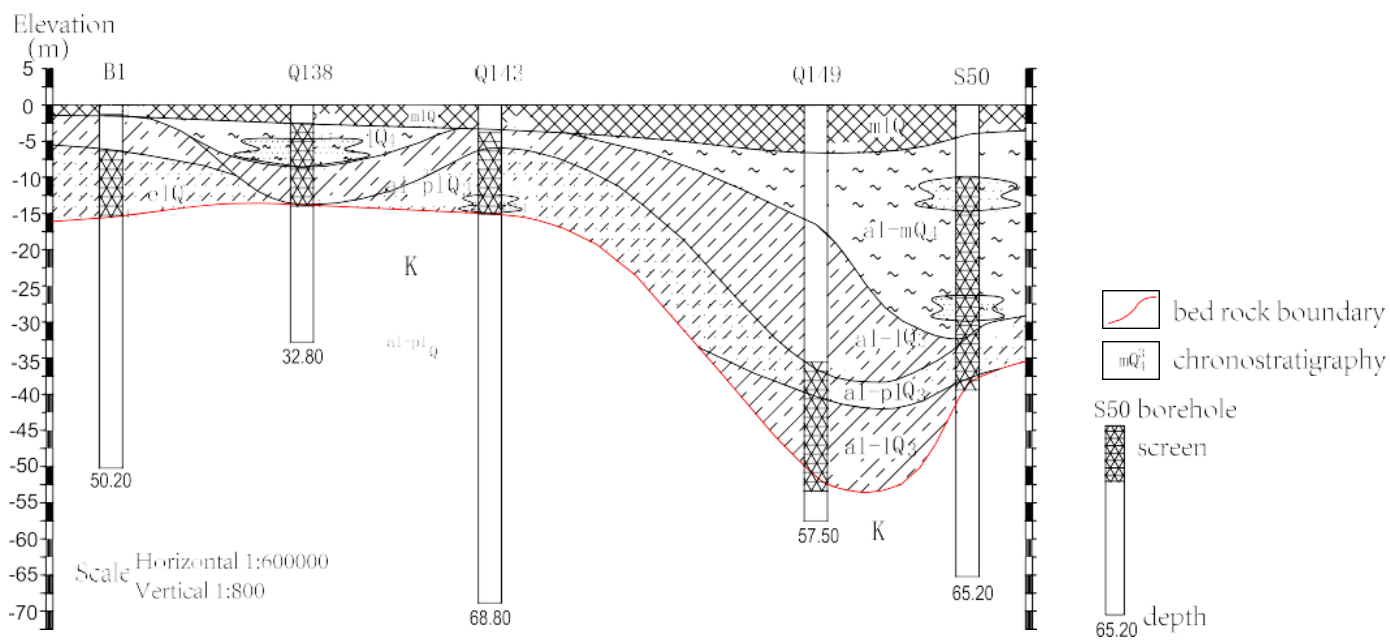

Fig. 2 Geologic units, shown in a cross section of monitoring wells S50 to B1

$s$ and translating along the localized time index $n$, one can construct a picture showing both the amplitude of any features versus the scale and the way this amplitude varies with time.

The difference between the two phases gives information about possible lags in the volatility of a time series as a function in the time-frequency domain. The cross-wavelet spectrum is useful for calculating the phases for both time series but can provide misleading results because it is only the product of two nonnormalized wavelet spectra (Maraun and Kurths 2004). The wavelet coherence (WTC) avoids this problem by normalizing the cross-wavelet spectrum to the single wavelet power spectrum as follows:

$$
\mathrm{WTC}=\frac{\left|W_{n}^{X Y}(s)\right|}{\left[W_{n}^{X}(s) W_{n}^{Y *}(s)\right]^{1 / 2}}
$$

The WTC ranges rom 0 to 1 and measures the cross correlation of two time series as a function of frequency (Torrence and Compo 1998). The results are interpreted as a correlation coefficient. There is strong cross-correlation between the two time series if the correlation coefficient is close to unity (Grinsted et al. 2004). As the wavelet is not completely localized in time, the cone of influence (COI) was introduced to remove the edge effects. Here, the COI is the area where the edge effect becomes important, and the wavelet power spectrum may not be regarded as real (Briciu 2014). The wavelet power was considered to confirm a true feature when the spectrum peak is significantly above the background spectrum (Grinsted et al. 2004).

\section{Time series analysis}

The cross-correlation analysis is used to establish a link between the input time series, $x_{n}$, and the output time series, $y_{n}$.

$$
r_{X Y}=E\left[\left(X_{t}-\mu_{X}\right)\left(Y_{t}-\mu_{Y}\right)\right] / \sigma_{X} \sigma_{Y}
$$

where $E$ is the expectation, $\mu_{\mathrm{x}}$ and $\mu_{\mathrm{y}}$ are the mean, and $\sigma_{x}$ and $\sigma_{y}$ are the standard deviation of the $x$ and $y$ time series, respectively.

\section{Results and discussion}

\section{Hydrological dataset}

From the pumping test, the saturated aquifer thickness $(b)$, the storativity $(S)$, and the saturated hydraulic conductivity $(K)$ were derived (see Table 1). These data are essential for understanding the estuarine groundwater system. The hydraulic conductivity is lowest in well S50, which is located within the thickest portion of the aquifer. The data from wells Q138 and Q149 suggest relatively higher $\mathrm{K}$ with smaller aquifer thicknesses.

Two months of data from continuous monitoring (May 25, 2017 to July 25, 2017) of precipitation, tidal level, and groundwater level were collected and used in the following analysis. The precipitation data measured at the WQS station and the tidal level variation data from the three gauge stations SNT, GZ and HP are illustrated in Fig. 3a,b, respectively. The figure shows that the tidal signal in the study area was mixed. The lower high-water level and higher low-water level did not occur on the same day but with a time lag of 3-4 days. High tides could be observed as far as $70 \mathrm{~km}$ upstream at the GZ station. For the three gauges, HP had the highest tidal level, and GZ had the lowest tidal level.

With a MATLAB-based Fourier transform of the tidal level at the SNT station, the tide is clearly dominated by a twice-aday cycle driven by the lunar semidiurnal constituent $\left(\mathrm{M}_{2}\right)$, with a period of $12.43 \mathrm{~h}$. The second constituent is diurnal variation, which includes two lunar constituents due to the declination of the moon's orbital plane, $\mathrm{K}_{1}$ and $\mathrm{O}_{1}$, with 
Table I Aquifer and aquitard lithology, hydraulic conductivity, thickness and storativity

\begin{tabular}{|c|c|c|c|c|}
\hline \multirow[t]{2}{*}{ Parameter } & \multicolumn{4}{|l|}{ Well } \\
\hline & $\mathrm{B} 1$ & Q138 & Q149 & $\mathrm{S} 50$ \\
\hline Aquifer & $\begin{array}{l}\text { Intermediary weathered } \\
\text { conglomerate with fractures }\end{array}$ & Strongly weathered conglomerate & Silty gravel sand & Sand and weathered gneiss \\
\hline Upper layer & Silty clay & $\begin{array}{l}\text { Muddy silt and weathered } \\
\text { mudstone and siltstone }\end{array}$ & Muddy and silty clay & Muddy silt and muddy clay \\
\hline$K(\mathrm{~m} /$ day $)$ & 0.33 & 3.19 & 3.60 & 0.06 \\
\hline$b(\mathrm{~m})$ & 7.00 & 0.60 & 3.80 & 40.70 \\
\hline$S(-)$ & $4.43 \cdot 10^{-5}$ & $2.06 \cdot 10^{-5}$ & $1.41 \cdot 10^{-4}$ & $3.38 \cdot 10^{-5}$ \\
\hline
\end{tabular}

$K$ hydraulic conductivity; $b$ aquifer thickness; $S$ storativity

periods of 25.81 and $23.99 \mathrm{~h}$, respectively. Two long-term periods are as well detected with small amplitudes and frequencies of 0.065 and 0.032 , which correspond to periods of 15.50 and 30.96 days, respectively.

To determine the connection between the precipitation and tidal data, groundwater level data from the four wells in the research area were displayed using double $y$-axes (Fig. 3c). The right $y$-axis represents the groundwater level in well B1 because it has a higher level relative to the other three wells, which correspond to the left axis. In the monitoring period, the water levels in Q138 and B1 presented rising trends. To investigate the reasons in detail, the water level and precipitation are compared, as shown in the shaded area in Fig. 3. The rising water level in B1 corresponded to precipitation events - for example, following $188.5 \mathrm{~mm}$ of rainfall on 16-19 June, the water level in well B1 increased approximately $0.5 \mathrm{~m}$, and similar trends can be observed in the following two events. The response time of groundwater level fluctuations in B1 


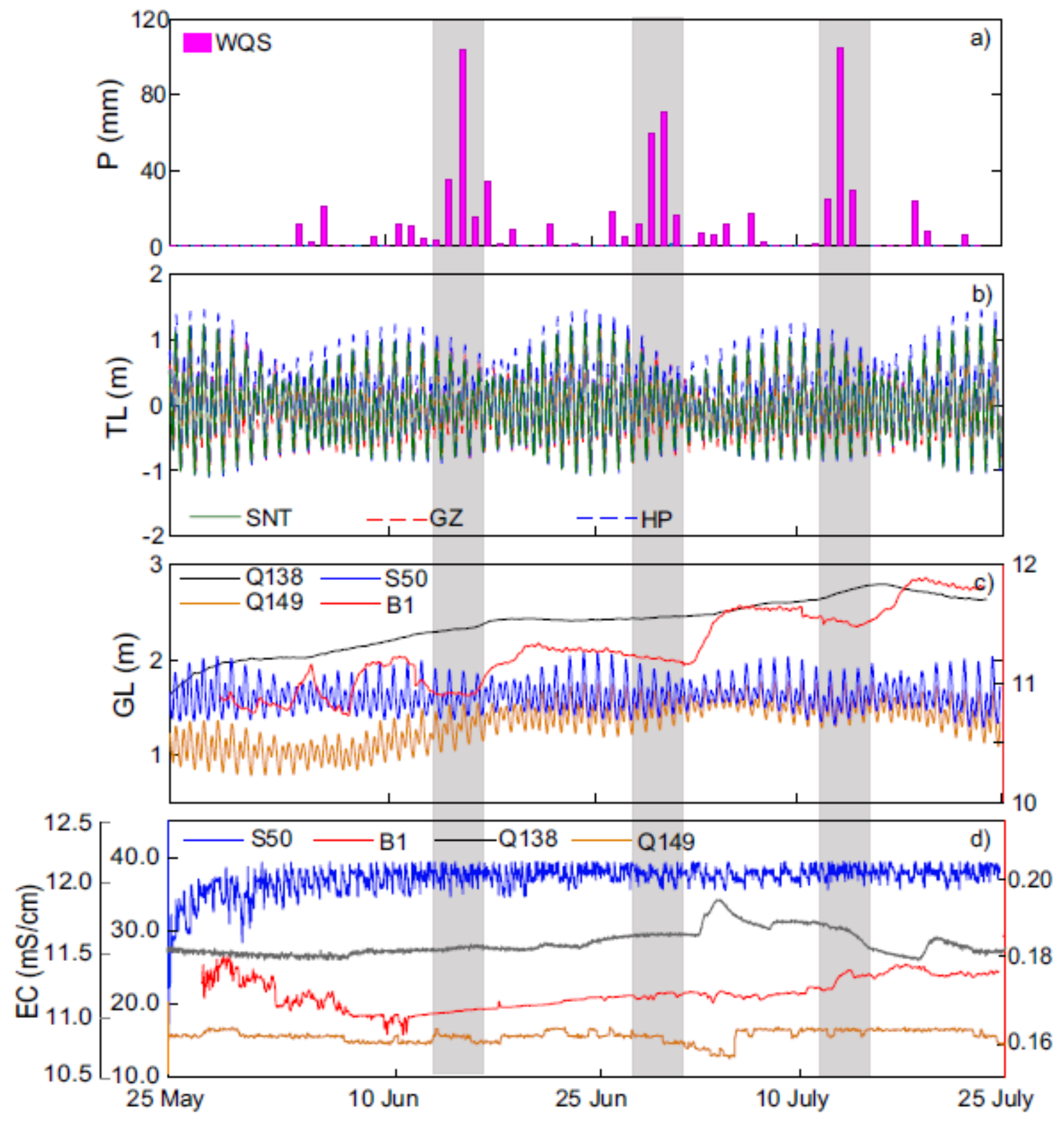

Fig. 3 a Precipitation (P) time series from the rain gauge, b temporal variations of tidal levels (TL) in tidal gauges, and c groundwater levels (GL) in wells in m above sea level (right y-axis represents B1), and d electrical conductivity (EC) in wells, from May 25 to July 27, 2017. WQS Wangqingsha tidal station; SNT Shuiniutu tidal station; GZ Guanzhou tidal station; HP Huangpu tidal station 
after rainfall was relatively long and ranged from 4 to 6 days. This long delay was because the hydrogeologic strata in well B1 are mainly composed of clay and silt with a low hydraulic conductivity of $0.33 \mathrm{~m} / \mathrm{day}$, which led to a slow infiltration process and long response time of groundwater level fluctuations. The groundwater level in well Q138 presented a stable rising trend without the stepped response pattern to precipitation observed in B1. This was largely due to the wells' geological characteristics. The upper low-permeability layer is $15 \mathrm{~m}$ thick in well $\mathrm{B} 1$ but is $27.5 \mathrm{~m}$ thick in Q138. Additionally, well Q138 consists of saturated mud and muddy silt. The high water holdup capacity and low permeability act as a buffer to stabilize the precipitation recharge to the aquifer. Correspondingly, the upper layer of B1 is sandy and silty clay, which have higher permeability values than muddy clay. This difference is also reflected by the groundwater level response of B1 to the tidal signal. Well Q138 was meters from the waterway, but the diurnal and semidiurnal signals from the tide were not significant.

In contrast to the two upstream wells B1 and Q138, Q149 and S50 were located in the south along the Hongwili waterway. The water level variations in these two wells were dominated by tidal impacts and had a clear cyclic pattern with two peaks daily, similar to the tide signals, as shown in Fig. 3b. Moreover, well S50 has a larger amplitude of groundwater level variation, which better followed the fluctuation of the tide due to location. In addition, no increasing trend was observed in the groundwater levels of S50. For Q149, the groundwater level increased starting in June. The preceding results demonstrated that the groundwater levels in the upstream areas were mainly driven by the climate and that those close to the open sea were mainly controlled by tide variations. Meanwhile, wells S50 and Q149 were screened in the same sandy aquifer. The higher groundwater level in S50 indicated saltwater intrusion from the south. The intrusion was more serious in May during a late dry period and weakened in July during a wet period with increasing lateral recharge from the north.

\section{WTC between tidal and groundwater levels}

The wavelet coherence was implemented to identify statistically significant relationships between tidal and groundwater levels. The WTC results estimated through tidal and groundwater levels at the four different wells are shown in Fig. 4, and the phase relationships between the spectra are portrayed by the directions of the arrows in the figure. Arrows pointing right represent time series that are in-phase, and those pointing left represent time series that are out-of-phase. The COI (white dashed line) shows the region of the wavelet spectrum where edge effects due to the finite-length nature of the underlying data cannot be ignored.
The WTC results display varied coherences between the groundwater level at each well and the tidal data from the closest tidal gauge. Statistically significant episodes of wavelet coherence at the scales of $0.25,0.5$ and 1-day periods could be observed in Q149 and S50. These periodicities were consistent with those of the tidal level: a semidiurnal 0.51-day periodicity between the two high tidal levels in a day from $\mathrm{M}_{2}$ and a 1.0-day diurnal periodicity between the highest tidal level each day from $\mathrm{O}_{1}, \mathrm{~K}_{1}$, and precipitation. This consistency reflected the direct influence of tidal impacts on Q149 and $\mathrm{S} 50$. The figures also demonstrate that the magnitude and the duration of the 0.51-day period were slightly stronger than the 1-day period for both wells, which represents a stronger tidal $\mathrm{M}_{2}$ signal influence on the groundwater level. For the other two wells located in the upstream area, B1 and Q138, the spectral magnitudes had low values throughout the time series (Fig. 4c,d).

These frequencies represent direct responses of groundwater levels to tidal variations. The phases of wavelet coherence periods were different between Q149 and S50, indicating that the tidal and groundwater levels were phase locked or synchronized in the 1-day period. However, for the 0.25 and 0.5 day periods, the paired time series were out-of-phase for S50. The arrows point upward to the right (approximately $45^{\circ}$ ) for the 550 results, which represent approximately $0.75-1.5 \mathrm{~h}$ of delayed responses of groundwater level change to the short periods ( 0.25 and 0.5 day) of tidal signals at the SNT station. This may be related to the fact that S50 was located farther from the SNT station than Q149. The results were justified because the SNT station was located between Q149 and S50; thus, the response to the $\mathrm{M}_{2}$ signal at the SNT site was different.

For wells B1 and Q138, the 0.25-day coherence was negligible, and the 1-day coherence was weak with low magnitude values in most observations. The magnitudes of the 0.5 day coherence were relatively high, but the associated distributions were intermittent at different times. Compared with the synchronized groundwater levels at Q138 and tidal data at GZ for the 0.5-day period (straight right-pointing arrows), the groundwater level at well B1 has different response times for tides at different times (variable arrow directions at different times). This may be due to B1's inland and upstream location and complex geological conditions. The biweekly coherence between HP and B1 was significant, with in-phase arrows, which illustrates that the groundwater changes due to the spring-neap cycle were more significant than semidiurnal or diurnal variation in this area. This can be explained by the fact that well B1 was located the farthest inland and far from the crossed waterways, and the tide influences with high frequencies were filtered out by the subsurface materials; thus, only the impacts with long periods could reach its location. In summary, the WTC shows that the groundwater levels in estuarine aquifers are all influenced by changes in tidal levels in the sea 
Fig. 4 a-d Wavelet coherence between groundwater levels at four wells and their adjacent tidalgauges; the dashed white lines denote the cone of influence (COI). The vectors indicate the phase difference between the data
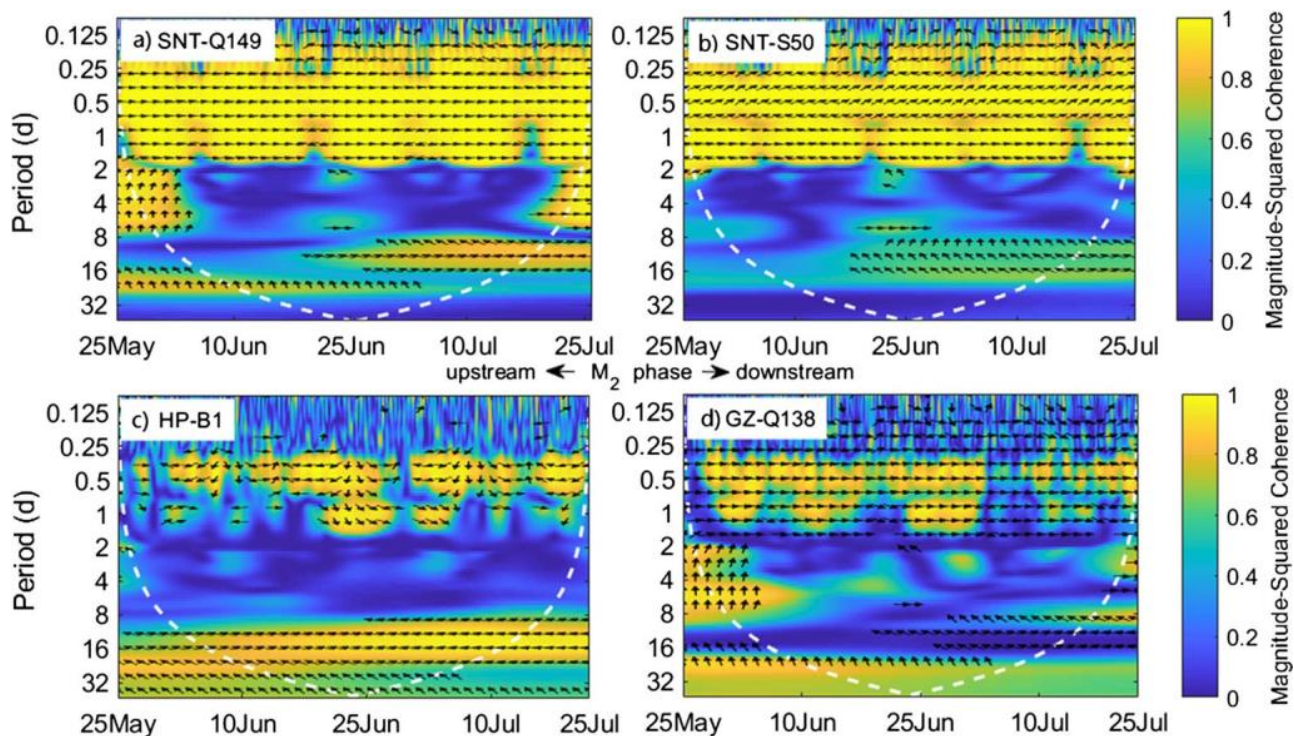

and waterways. The different influences of tidal signals on groundwater levels were spatially and temporally variable. The areas away from the waterways are more likely to be affected by small, long-delayed and long-period tidal impacts than wells that are close to the sea or waterways. Moreover, the tidal effects on certain areas were generally correlated to the combined effect from their locations relative to the sea or waterway and geological conditions.

\section{WTC between tidal and groundwater EC}

When the WTC analysis was applied to the monitored groundwater electrical conductivity (EC) data and tidal level time series, no continuous short-term temporal correlations were detected in the four wells, as shown in Fig. 5. Long periods of correlation of 8-12 days, between 20 June and 10 July, were detected for Q149 and B1 and were more significant for B1. The results represented a salinity cycle with a neap or neap-spring tide in which the groundwater salinity tends to change over long-time period scales than exhibiting shortterm variations caused by $\mathrm{M}_{2}$ or $\mathrm{O}_{1}$ and $\mathrm{K}_{1}$. The 0.5 -day periodicity was found at high tide levels in S50 and B1. No obvious influence from tidal level can be detected in either the short or long term at Q138. This there is no response of EC to lunar tidal signals for Q138.

Although Q149 and S50 were both located along the Hongwili waterway and had similar groundwater level variations, their EC responses to the tidal variation are different (Fig. 5a,b). The EC in Q149 has no obvious correlation with the tidal variations. However, for S50 the left-pointing arrows indicate that as EC decreases the groundwater level increases. In general, EC often increases by salt water intrusion. However, the salinity in S50 is higher than that of seawater, thus the EC decreased from mixing with seawater. Another
Fig. 5 a-d Wavelet coherence between electrical conductivity values at four wells and their adjacent tidal gauges; the dashedwhite lines denote the COI. The vectors indicate the phase difference between the data
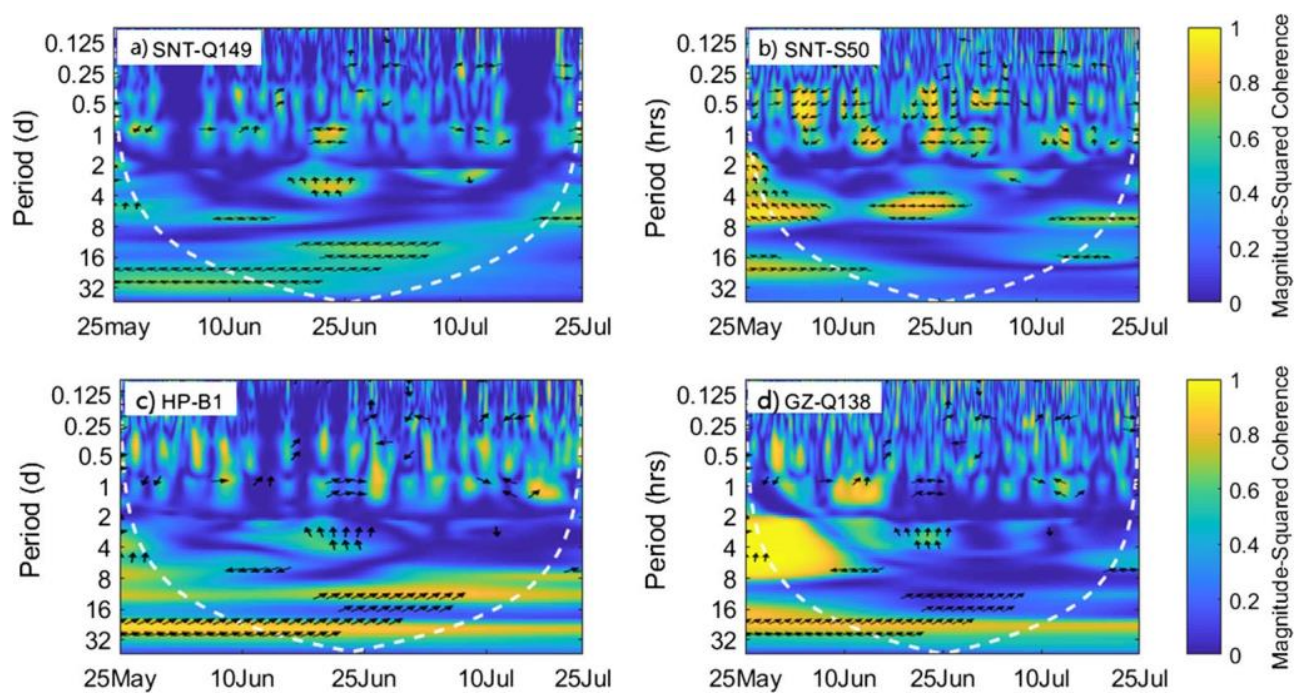

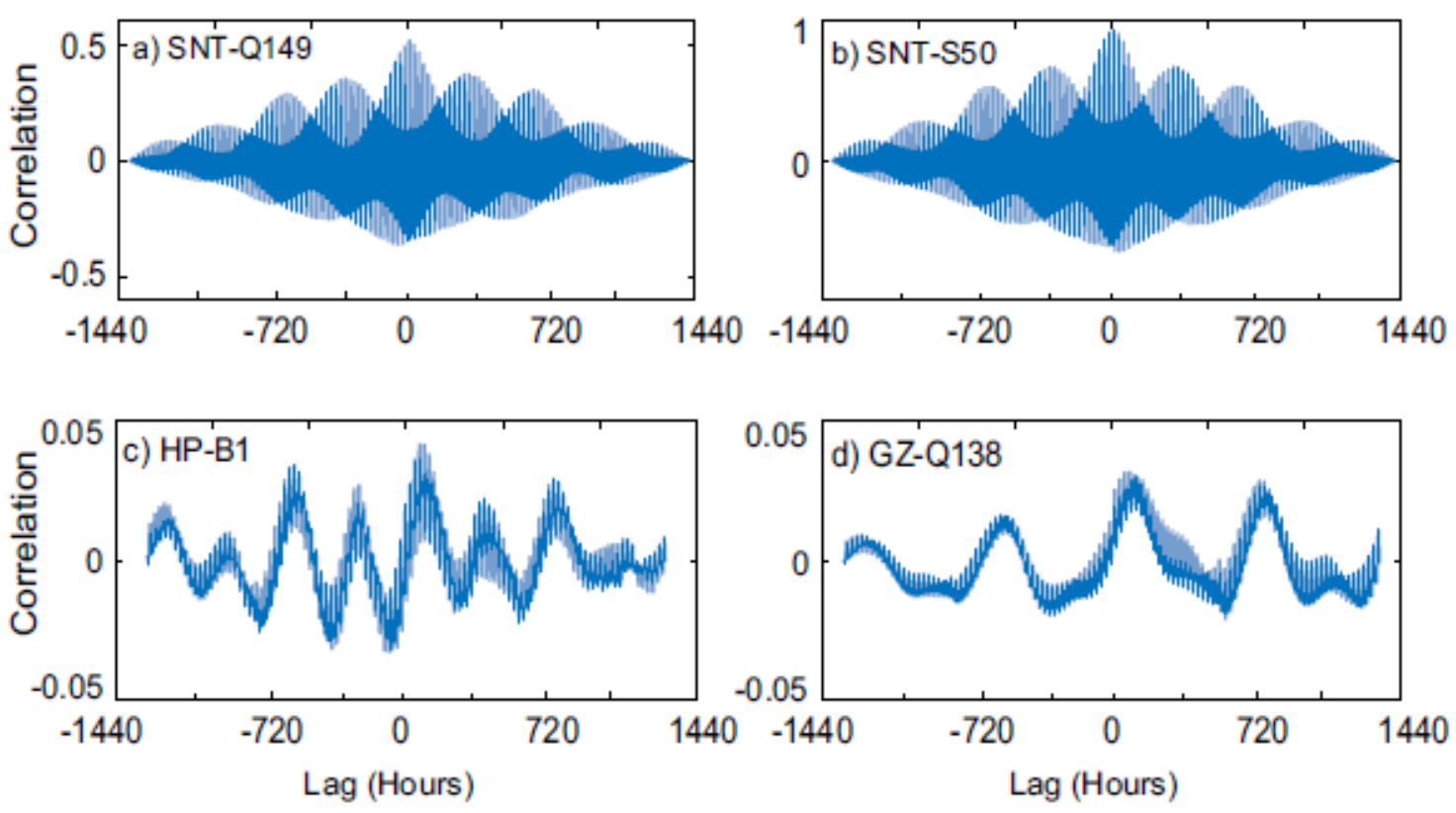

Fig. 6 a-d Cross-correlation functions of tidal level as input and groundwater level as output between time series pairs

factor that affected the EC responding to the tides was the groundwater-level fluctuation patterns. Moreover, silt or clay in the screening depth of Q149 was associated with higher porosity and lower permeability than sand in that of S50, which may limit the groundwater exchange in Q149. Furthermore, the tidal influences on groundwater EC are weak compared to those on groundwater levels because the groundwater level fluctuation is a response to the stress variation and the EC variation requires a volume change in the water stored in the aquifer. More importantly, geologic conditions are crucial to controlling the tidal effect on groundwater levels. The stress transfer is limited if the aquifer thickness is minor.

\section{Tidal signal, groundwater level, and EC cross-correlations}

The cross-correlation function was calculated to investigate the lag time between the tide and the groundwater levels. In the analysis, the tidal level was used as the input, and the groundwater level was used as the output. Correlations of $0.52,0.94,0.05$ and 0.03 were observed as the maximum values in Q149, S50, B1, and Q138, respectively (Fig. 6). The correlation was the largest in S50, which shows that the variation patterns of the two signals were quite similar. Therefore, the groundwater level in S50 could be simply predicted by referencing tidal-level variations in the waterway. Long-term repeated trends were observed every 14 days, which corresponded to the spring/neap tide cycle. Meanwhile, the correlations decreased when the time lags of the two signals increased. The correlation pattern for Q149 was similar to that for S50 but with a smaller value. The time lags of Q149 and S50 were approximately $1 \mathrm{~h}$. The highest values of the correlation coefficient and small lag times reflected a strong tidal effect on the groundwater levels in Q149 and S50, which were only a few meters away from the waterway. The cross-correlation patterns for B1 and 

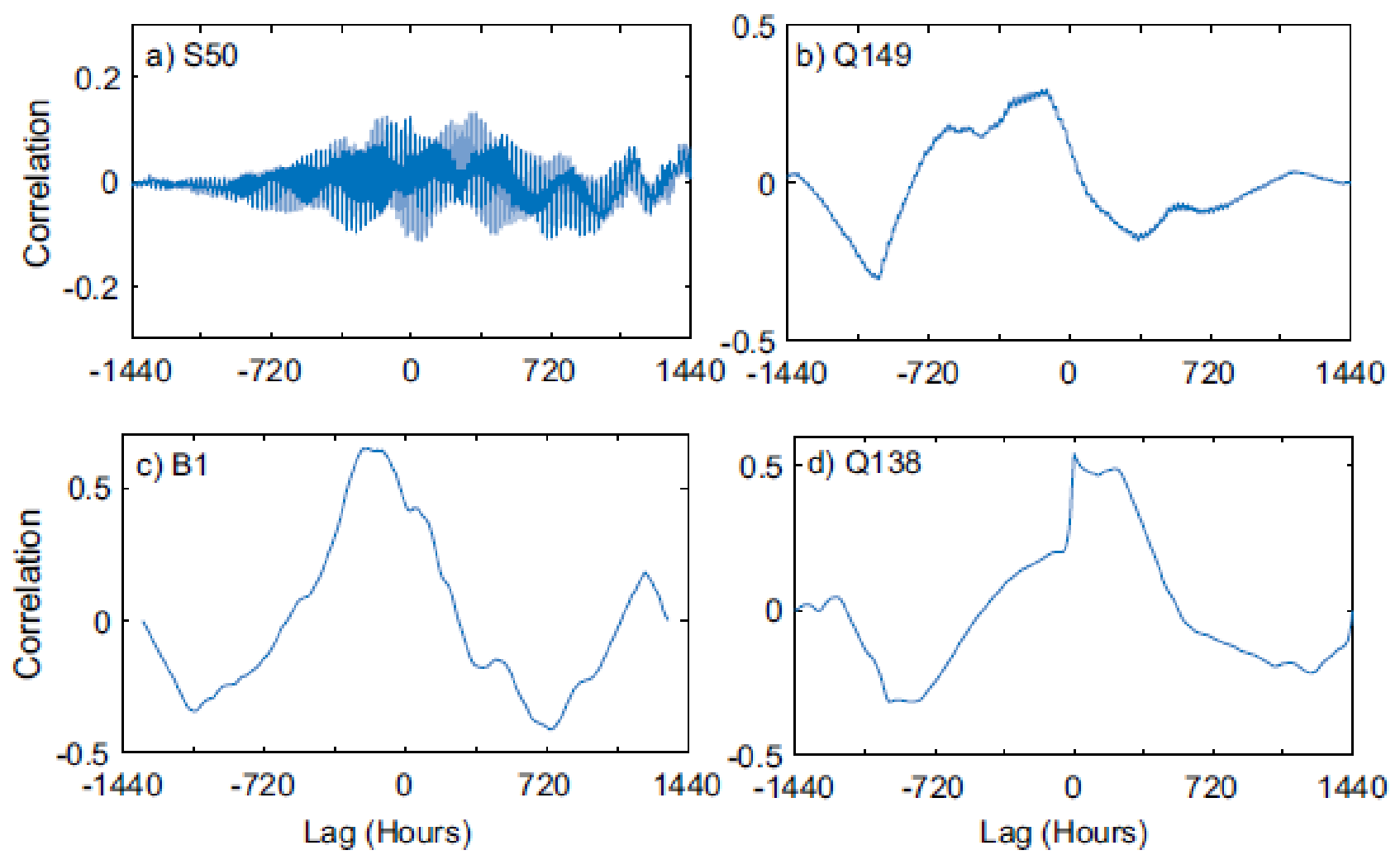

Fig. 7 a-d Cross-correlation functions of electrical conductivity as output with groundwater levels time series as input for the four wells

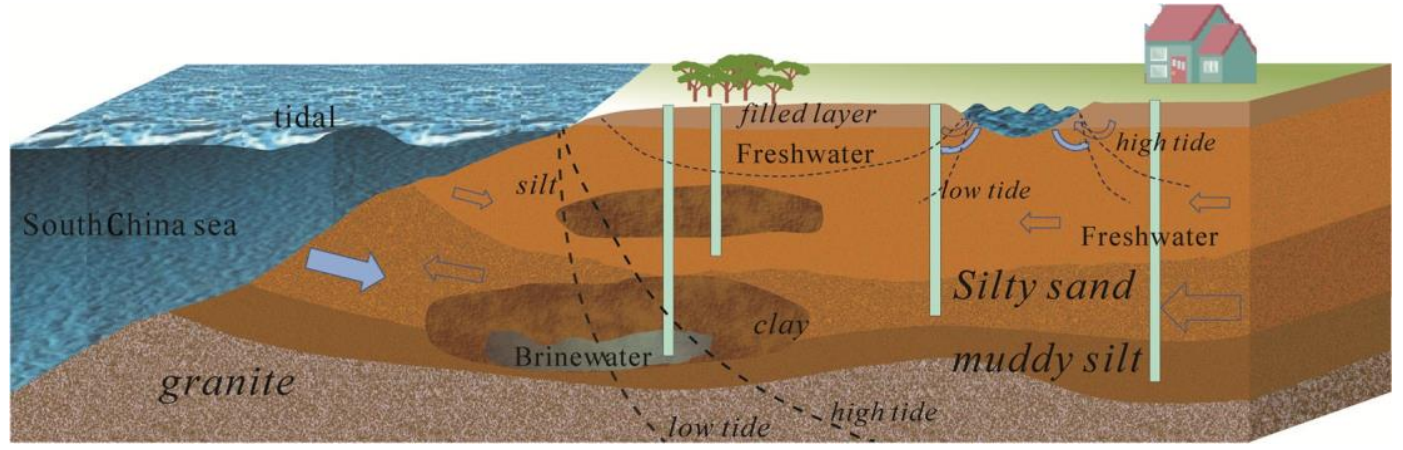

Fig. 8 Schematic diagram of the tidal fluctuation effect on the groundwater dynamics in the estuary subsurface, with currents in the waterways. The blue arrows represent a recharge from saltwater, and the transparent arrows represent a recharge from freshwater. The polygons that cross the sediment layers represent trapped water lenses. With the variation of high/low tides and spring/neap tides, the saltwater- freshwater interface moves forward and backward in the subsurface 
Q138 were different from those for Q149 and S50. The cor- relations also demonstrated repeated semidiurnal trends and local positive higher correlations between the tidal level at theHP station and the groundwater levels in B1. However, for theGZ station and Q138, the time lag of local higher correlationwas one lunar month; nevertheless, the largest correlation co-efficients for B1 and Q138 were both less than 0.05 , whichrepresents weak tidal impacts at both sites. Meanwhile, the correlation cycles in all four wells reflected higher correlationsduring the spring tide and lower correlations during the neaptide, which suggests that the higher tidal levels have strongerand faster effects on the groundwater level.

The cross-correlation between groundwater level and EC ispresented in Fig. 7. Two types of correlation existed in the fourwells. S50 exhibited cyclic correlation between tide and groundwater EC, indicating that EC had a periodic variation; hence, the EC variation had a relatively close relationship with the tidal variation. The largest negative correlation was foundat lag time zero, which illustrates that the higher groundwater levels and lower EC values occurred simultaneously. The phe-nomenon was due to the higher salinity of the groundwater, which had been stored in the closed clay sediment layers sincethe late Holocene, than that of the water in the estuarine waterway. The results of the other wells showed that the EC exhibited different behavior with negative elapsed time in each well, implying that the EC was correlated with the past groundwater level. With increasing groundwater level, the ECchanged in proportion to the groundwater level on the scale ofdays. In addition, significant negative coefficients were found at two sides with advanced and delayed correlations of 15-40 days. Monitoring for a longer time or period is needed toinvestigate the correlation over a long-term period.

\section{Conceptual model}

Based on the results of temporal and correlation analyses oftidal level, groundwater level and EC, a conceptual model was proposed for the tidal influence on groundwater dynamics in the estuary based on the change in tidal level. The conceptualmodel of water interactions in the study area is given in Fig. 8.In flood or spring tides, as the tidal level increases, the ground- water level gradually increases accordingly with time lags. This depends on the geographical location. At the same time, seawater is transported into the subsurface and mixes with the ambient groundwater. As a result, the groundwater EC variesdue to mixing of the surface water and groundwater with different salinities. If the groundwater is saltier than that of surface water (e.g. well S50 in this study), the groundwater freshening may occur. Thus, EC decreases and the seawater-groundwater interface moves landward; otherwise, groundwa ter becomes saltier, and the seawater-freshwater interface moves landward. During the ebb or neap period, the tidal leveldecreases, the amount of infiltrating seawater is low, or groundwater is discharged to the ocean. As a result, seawaterrecedes from the land and the interfaces move seaward.

\section{Conclusions}

Different data analysis methods were implemented to investi- gate the groundwater dynamics under the hydrologic stressesof tidal and precipitation fluctuations in the Pearl River estu-arine aquifer. Different analysis methods demonstrate differ-ent aspects of patterns in groundwater dynamics.

The WTC analysis shows the groundwater levels in estua-rine aquifers are all influenced by changes in tidal levels in the

sea and waterways. However, strengths of these influences vary because of the locations and geological conditions. Time series analysis also provided useful results, yielding dif- ferent correlation coefficients and lagging times at the four wells. Comparison of the crosscorrelation results between the spring and the neap tide reveals that the maximum valueis higher during spring tides than during neap tides, which implies that the groundwater dynamic patterns also have a temporal variation.he techniques described in this report are valuable to otherstudies of nonlinear, time-dependent groundwater dynamics in coastal areas. The possible applications include analyses of internal tides, short internal wave dynamics, effects of at-mospheric forcing and the detection of long-term climate trends. The results are also helpful for coastal management and can be extended to other areas with similar geographicalconditions.

Funding information This work was supported by the National NaturalScience Foundation of China (41702244, 41807182); the China Postdoctoral Science Foundation (2015 M582479); the JLU Science and Technology Innovative Research Team (JLUSTIRT 2019TD-35); Western Light-western region supporting leading scientists project; Chinese Academy of Sciences (2018XBYJRC-002) and the Guangzhou Water Science and Technology Project (PSZX-XSRQDXS-201601).

\section{Compliance with ethical standards}

Competing interests The author(s) declare no competing interests. 


\section{References}

Antonellini M, Allen DM, Mollema PN, Capo D, Greggio N (2015) Groundwater freshening following coastal progradation and land reclamation of the Po Plain, Italy. Hydrogeol J 23:1009-1026

Ataie-Ashtiani B, Volker RE, Lockington DA (1999) Tidal effects on sea water intrusion in unconfined aquifers. J Hydrol 216(1-2):17-31

Ataie-Ashtiani B, Volker RE, Lockington DA (2001) Tidal effects on groundwater dynamics in unconfined aquifers. Hydrol Process 15: 655-669

Box GEP, Jenkins GM, Reinsel GC (1994) Time series analysis: forecasting and control. Prentice-Hall, Englewood Cliffs, NJ

Briciu AE (2014) Wavelet analysis of lunar semidiurnal tidal influence on selected inland rivers across the globe. Sci Rep 4(4193):1-12

Brown I (2006) Modeling future landscape change on coastal floodplain using a rule-based GIS. Environ Model Softw 21:1479-1490

Burnett WC, Bokuniewicz H, Juettel M (2003) Groundwater and pore water inputs to the coastal zone. Biogeochemistry 66(1-2):3-33

Byun DS, Wang XH, Holloway PE (2004) Tidal characteristic adjustment due to dyke and seawall construction in the Mokpo coastal zone, Korea. Estuarine Coastal Shelf Sci 59:185-196

Carr PA, Van Der Kamp GS (1969) Determining aquifer characteristics by tidal method. Water Resour Res 5(5):1023-1031

Dai Z, Samper J (2006) Inverse modeling of water flow and multicomponent reactive transport in coastal aquifer systems. J Hydrol 327: 447-461

Dai Z, Keating E, Bacon D, Viswanathan H, Pawar R (2014) Probabilistic evaluation for shallow groundwater resources at a potential carbon sequestration site. Sci Rep 4:4006

Daubechies I (1992) Ten lectures on wavelets. Society for Industrial and Applied Mathematics, Philadelphia, PA

Dong L, Shimada J, Kagabu M, Yang H (2015) Barometric and tidalinduced aquifer water level fluctuation near the Ariake Sea. Environ Monit Assess 187:4187

Essink GHP, van Baaren ES, de Louw PGB (2010) Effects of climate change on coastal groundwater systems: a modeling study in the Netherlands. Water Resour Res 46(10):1-16

Galli AW, Heydt GT, Ribeiro PF (1996) Exploring the power of wavelet analysis. IEEE Comput Appl Power 9(4):37-41

Global Water Partnership (GWP) (2016) China, Pearl River Delta Demonstration Project. GWP, Stockhom, 45 pp

Gribovszki Z, Szilagyi J, Kalicz P (2010) Diurnal fluctuations in shallow groundwater levels and streamflow rates and their interpretation: areview. J Hydrol 385:371-383

Grinsted A, Jevrejeva S, Moore J (2004) Application of the cross wavelet transform and wavelet coherence to geophysical time series. Nonlinear Process Geophys 11:561-566

Holman IP, Rivas-Casado M, Bloomfield JP, Gurdak JJ (2011) Identifying non-stationary groundwater level response to North Atlantic Ocean-atmosphere teleconnection patterns using wavelet coherence. Hydrogeol J 19:1269-1278

Jay DA, Leffler K, Diefenderfer HL, Borde AB (2015) Tidal-fluvial and estuarine processes in the Lower Columbia River: I. along-channel water level variations, Pacific Ocean to Bonneville Dam. Estuaries Coasts 38(2):415-433

Jiao JJ, Tang Z (1999) An analytical solution of groundwater response to tidal fluctuation in a leaky confined aquifer. Water Resour Res 35(3): $747-751$

Kang S, Lin H (2007) Wavelet analysis of hydrological and water quality signals in an agricultural watershed. J Hydrol 338:1-14

Kim J, Lee J, Cheong TJ, Kim RH, Dong CK, Jong SR, Chang HW (2005) Use of time series analysis for the identification of tidal effect on groundwater in the coastal area of Kimje, Kora. J Hydrol 300(14):188-198

Kim T, Lee KK, Ko KS, Chang HW (2000) Groundwater flow system inferred from hydraulic stresses and heads at an underground LPG storage cavern site. J Hydrol 236:165-184

Li H, Zhao Q, Boufadel MC, Venosa AD (2007) A universal nutrient application strategy for the bioremediation of oil-polluted beaches. Mar Pollut Bull 54(8):1146-1161

Li L, Barry DA, Stagnitti F, Parlange JY, Jeng DS (2000) Beach water table fluctuations due to spring-neap tides: moving boundary effects. Adv Water Resour 23:817-824

Li X, Shen Z, Wai, OWH, Li YS (2001) Chemical forms of Pb, Zn and cu in the sediment profiles of the Pearl River estuary. Mar Pollut Bull 42(3):215-223

Liu C, Franz TF, Jie W, Dong Y, Yang T, Yin J, Wang Y, Liu M (2013) Late Quaternary palaeoenvironmental changes documented by microfaunas and shell stable isotopes in the southern Pearl River Delta plain. J Palaeogeogr 2(4):344-361

Liu Y, Shang S, Mao X (2012) Tidal effects on groundwater dynamics in coastal aquifer under different beaches slopes. J Hydrodyn 24:97106

Mao X, Enot P, Barry DA, Li L, Binley A, Jeng DS (2006) Tidal influence on behaviour of a coastal aquifer adjacent to a low-relief estuary. J Hydrol 327:110-127

Maraun D, Kurths J (2004) Cross wavelet analysis: significance testing and pitfalls. Nonlinear Proc Geophys 11:505-514

Nejad FH, Nourani V (2012) Elevation of wavelet denoising performance via an ANN-based streamflow forecasting model. Int J Comput Sci Manag Res 1(4):764-770

Nielsen P (1990) Tidal dynamics of the water table in beaches. Water Resour Res 26:2127-2134

Parizi E, Hosseini SM, Ataie-Ashtiani B, Simmons CT (2019) Vulnerability mapping of coastal aquifers to seawater intrusion: review, development and application. J Hydrol 570:555-573

Robinson C, Gibbes B, Li L (2006) Driving mechanisms for groundwater flow and salt transport in a subterranean estuary. Geophys Res Lett 33:L03402

Torrence C, Compo GP (1998) A practical guide to wavelet analysis. Bull Am Meteorol Soc 79(1):61-78

Turner IL (1995) Simulating the influence of groundwater seepage on sediment transported by the sweep of the swash zone across macrotidal beaches. Mar Geol 125(1-2):153-174

Van der Kamp G, Gale JE (1983) Theory of earth tide and barometric effects in porous formations with compressible grains. Water Resour Res 19:538-544

Wallace CD, Sawyer AH, Barnes RT (2019) Spectral analysis of continuous redox data reveals geochemical dynamics near the stream

Werner AD, Bakker M, Post VE, Vandenbohede A, Lu C, Ataie-Ashtiani B, Simmons CT, Barry DA (2013) Seawater intrusion processes, investigation and management: recent advances and future challenges. Adv Water Resour 51:3-26

Zhang X, Miao J, Hu BX, Liu H, Zhang H, Ma Z (2017) Hydrogeochemical characterization and groundwater quality assessment in intruded coastal brine aquifers (Laizhou Bay, China). Environ Sci Pollut Res 24:21073-21090 